\title{
Prevalence of Incisor Relationship Anomalies in an Algerian Orthodontic Population: Influence in Frequency of Orthodontic Extraction
}

\author{
Farida Ammouche* \\ MUHC Algiers, Algeria \\ *Corresponding author: Farida Ammouche, MUHC Algiers, Algeria
}

\begin{abstract}
In a study of therapeutic extractions in orthodontics, incisor relationship anomalies were described in the three planes of space: transverse, vertical and sagittal planes. 664 patients were considered among them, a large number had occlusal disorders in the anterior sector: we mainly observed midline discrepancies $(69,6 \%)$, deep bite $(48 \%)$, open bite $(27,6 \%)$, proclination $(61,1 \%)$, retroclination $(26,2 \%)$. Incisor relationship intervenes in our therapeutic choices, particularly with regard to extracting or not, but can be an indicator in favour of screening and early treatment.
\end{abstract}

Keywords: Incisor relationship anomalies, Three planes of space, Therapeutic choices

\section{Introduction}

Incisor relationship anomalies are the main reason for consultation among our patients, especially when they are associated with dental crowding. The reason is that the impact is felt on the aesthetic of the smile essential parameter of the demand for orthodontic treatments [1]. The clinical form and degree of severity [2,3] depend on the etiological factors and the relevant dentoalveolar or skeletal structures involved in the onset of incisor relationship abnormalities. The therapeutic approach is chosen considering these factors but also the age of the patient and the stage of growth. In most cases, it is preferable to opt for early treatment mainly when the problem is dentoalveolar or functional, the chances of success are greater in the short and long term $[4,5]$.

Thus, when the treatment is late, extraction can be necessary to correct the incisor relationship anomalies mostly if dental crowding or skeletal malocclusions are associated.

\section{Material and Method}

Our study involved an Algerian orthodontic population of 664 subjects ( 372 girls and 292 boys). All individuals meeting the inclusion criteria were selected. Mean age was twelve. Patients were excluded if they had primary dentition, lost permanent teeth or were more than 16 years old. Incisor relationship has been raised for the entire population in the three planes of space. The calculation of the percentage of occlusal anomalies was made to describe the sample and evaluate the frequency of orthodontic extraction. The incisor relationship was examined and measured by referring to the midline for transverse plane, the overbite for vertical plane and the overjet for sagittal plane. The frequency of extraction had been evaluated considering the incisor relationship.

\section{Results}

Among the total patients included in this study, the frequency of orthodontic extraction was 52,6\%, 349 patients had been treated with extraction of definitive teeth. The prevalence of incisor relationship anomalies differs from one plane of space to another. The results showed a major percentage of individuals with incisor midline discrepancies in our selected group $(69,6 \%)$. Deep bite was also predominant in our sample, $48 \%$ of patients had an exaggerated overlap. In the sagittal plane, results showed the predominating of incisor proclination with a rate of $61.1 \%$. The percentages of extractions vary according to the type of anomalies but are more important in cases of midline discrepancies and incisor proclination (Tables 1-4). 
Table 1: Distribution of Patients According to Transverse Incisor Relationship.

\begin{tabular}{|c|c|c|}
\hline Transverse Incisor Relationship & N & \% \\
\hline Normal Relationship & 202 & $30,4 \%$ \\
\hline Midline Discrepancies & 462 & $69,6 \%$ \\
\hline Total & 664 & $100 \%$ \\
\hline
\end{tabular}

Table 2: Distribution of Patients According to Vertical Incisor Relationship.

\begin{tabular}{|c|c|c|}
\hline Vertical Incisor Relationship & $\mathbf{N}$ & $\mathbf{\%}$ \\
\hline Normal Relationship & 162 & $24,4 \%$ \\
\hline Deep Bite & 319 & $48,0 \%$ \\
\hline Open Bite & 183 & $27,6 \%$ \\
\hline Total & 664 & $100 \%$ \\
\hline
\end{tabular}

Table 3: Distribution of Patients According to Sagittal Incisor Relationship.

\begin{tabular}{|c|c|c|}
\hline Sagittal Incisor Relationship & N & \% \\
\hline Normal Relationship & 84 & $12,7 \%$ \\
\hline Proclination & 406 & $61,1 \%$ \\
\hline Rétroclination & 174 & $26,2 \%$ \\
\hline Total & 664 & $100 \%$ \\
\hline
\end{tabular}

Table 4: Extraction Percentages in Incisor Relationship Anomalies Among the Group Treated with Extraction (N=349).

\begin{tabular}{|c|c|c|}
\hline Incisors Relationship Anomalies & N & $\begin{array}{c}\text { Frequency of } \\
\text { Extraction }\end{array}$ \\
\hline Midline Discrepancies & 259 & $74,2 \%$ \\
\hline Deep Bite & 163 & $46,7 \%$ \\
\hline Open Bite & 98 & $28,1 \%$ \\
\hline Proclination & 206 & $59 \%$ \\
\hline Retroclination & 95 & $27,2 \%$ \\
\hline
\end{tabular}

\section{Discussion}

The frequency of orthodontic extraction among the total sample was $52,6 \%$. Incisor relationship anomalies prevalence is important but different from a plane to another: transverse $69,6 \%$, vertical $75,6 \%$, sagittal $87,3 \%$. The study showed that the criteria for extraction concerned mostly the dental crowding and class II skeletal malocclusion [6]. So, the variability of extraction percentage in incisor relationship anomalies can be explained in different ways. It is possible to consider the aesthetic as an influencing criterion in the decision to extract since the incisor relationship affects the smile and the profile [7]. But it can't be the only explanation.

Midline discrepancies, deep bite, proclination are the most numerous among our patients and the most concerned in extraction, the lack of space on the dental arches may explain the decision to extract. This is in keeping with the fact that incisor relationship anomalies are often associated with skeletal malocclusions or dental crowding [8,9]. The incisor proclination when pronounced requires a large incisor repositioning and consequently space on the arches. Often associated with Class II skeletal discrepancy and dental crowding, the exaggerated overhang is corrected by dental extractions and incisor recoil. Concerning midline discrepancies and deep bite, the same conclusions can be drawn although there may be contraindications for deep bite: extraction is related to the amplitude of the deviation and the presence of various associated anomalies.

So, in all cases, the results showed orthodontic extractions justified by usual criteria $[6,10]$ but late treatment knowing that the mean age among the population was twelve and the insufficiency of early and functional therapies may explain the high percentages of extraction too $[11,12]$.

\section{Conclusion}

Our study showed a high prevalence of incisor relationship anomalies and high percentages of orthodontic extractions. The reason for extraction varies according to each clinical case. Differences in the clinical form of malocclusions may help to understand those related to the therapeutic choice mostly when extraction is indicated. This can be related to the impact of anomalies on the aesthetic of the smile and profile but also to the associated anomalies which are dental crowding and skeletal malocclusions. Moreover, when the treatment starts late, it is done with more extraction because the possibilities of gaining space decreases when anomalies are severe. So, the conclusion is that to reduce the frequency of orthodontic extraction, it is necessary to prevent the appearance of these anomalies or to intercept them early using alternative therapies as expansion or molar distalization.

\section{References}

1. Van Der Geld P, Oosterveld P, Van Heck G, Kuijpers Jagtman AM (2007) Smile attractiveness: Self-perception and Influence on Personality Angle Orthod. 77, $\mathrm{N}^{\circ} 5$ : 759-65.

2. Bibby RE (1980) Incisor relationship in different skeletal facial patterns Angle Orthod. 50, $\mathrm{N}^{\circ} 1: 41-4$.

3. Dolce C, Alfonso M (2019) Analysis of occlusion Dentalcare.com. Page 8.

4. Patti A, Perrier D Arc G (2005) Clinical Success in Early Orthodontic Treatment Quintessence Publishing France. 124p.

5. Proffit WR (2003) The timing of orthodontic treatment: Effectiveness and Efficiency Rev Odont Stomat. $32: 171-89$.

6. Ammouche F, Ahmed F Si (2015) Assessment of therapeutic extraction rates and criteria in orthodontics Epidemiological study in the dentofacial orthopedics department of the Mustapha University Hospital Algiers. J Dentofacial Anom Orthod 18, N³: 314.

7. Burrow JS (2008) To extract or not to extract: A diagnostic decision not a marketing decision. Am J Orthod Dento Facial Orthop 133(3): 341-42.

8. Bernabé E, Flores-Mir C(2006) Dental morphology and crowding Angle Orthod. $76, \mathrm{~N}^{\circ} 1: 20-5$ 
9. Bills DA, Handelman CS, Begole EA (2005) Bimaxillary dentoalveolar protrusion: traits and orthodontic correction Angle Orthod. 75, $\mathrm{N}^{\circ} 3$ : 333-39.

10. De Brondeau F, Boileau MJ, Duhart AM (2001) Impact esthétique des extractions Rev Orthop Dento Faciale. 35 : 251-73.
11. Arvystas MG (1998) Arguments en faveur du traitement orthodontique précoce Am J Orthod Dentofacial Orthop 4, ํ2 2 :74-7.

12. Stöckli PW (1995) Functional appliances and the extraction/ no extraction decision In : Bolender CJ, Bounoure G.M Barat Y eds Extraction versus no extraction. Paris: SID: 19- 44.

\section{(c) (i) This work is licensed under Creative}

To Submit Your Article Click Here: Submit Article

DOI: 10.32474/MADOHC.2019.03.000170

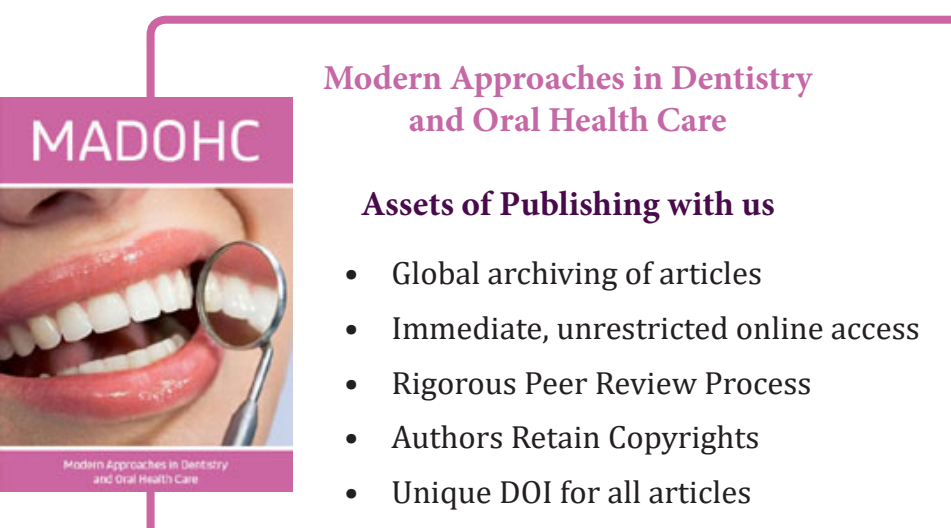

